\title{
Volcanic plume and bomb field masses from thermal infrared camera imagery
}

\author{
A.J.L. Harris ${ }^{\text {a,* }}$, D. Delle Donne ${ }^{\text {b }}$, J. Dehn ${ }^{c}$, M. Ripepe ${ }^{\mathrm{b}}$, A.K. Worden ${ }^{\mathrm{c}}$ \\ a Laboratoire Magmas et Volcans, Université Blaise Pascal, 63038 Clermont-Ferrand, France \\ b Dipartimento di Scienze della Terra, Universita di Firenze, via G. La Pira, 4, 50121 Firenze, Italy \\ ' Alaska Volcano Observatory, Geophysical Institute, University of Alaska Fairbanks, Fairbanks, AK 99775, USA
}

\section{A R T I C L E I N F O}

\section{Article history:}

Received 23 March 2012

Received in revised form 5 December 2012

Accepted 7 January 2013

Editor: T. Elliott

\section{Keywords:}

volcanic explosion

thermal camera

mass

volume

heat flux

\begin{abstract}
A B S T R A C T
Masses erupted during normal explosions at Stromboli volcano (Italy) are notoriously difficult to measure. We present a method that uses thermal infrared video for cooling bomb fields to obtain the total power emitted by all hot particles emitted during an explosion. A given mass of magma $(M)$ will emit a finite amount of thermal power, defined by $M c_{p}\left(T_{e}-T_{0}\right), c_{p}$ and $T_{e}$ being magma specific heat capacity and temperature, and $T_{0}$ being ambient temperature. We use this relation to convert the total power emitted by the bomb field to the mass required to generate that power. To do this we extract power flux curves for the field and integrate this through time to obtain total power $(E)$. This is used to estimate mass $(Q)$ in $Q=E / c_{p}\left(T_{e}-T_{0}\right)$. When applied to individual bombs we obtain masses of between 1 and $9 \mathrm{~kg}$ per bomb, or a volume of 970 and $6500 \mathrm{~cm}^{3}$. These volumes equate to spheres with diameters 12 and $27 \mathrm{~cm}$. For the entire bomb field we obtain volumes of 7-28 $\mathrm{m}^{3}$. We calculate masses for 32 eruptions and obtain typical bomb masses of between $10^{3}$ and $10^{4} \mathrm{~kg}$ per eruption. In addition, we estimate that between $10^{2}$ and $10^{3} \mathrm{~kg}$ of gas and ash are emitted as part of a mixed plume of bombs, gas and ash. We identify two types of eruption on the basis of the erupted bomb masses and the ratio of the plume's gas-and-ash component to the bomb component. The first type is bomb-dominated, is characterized by bomb masses of $10^{4} \mathrm{~kg}$ and has ash-gas/ bomb ratios of $\sim 0.02$. The second type is ash-and-gas dominated, is characterized by erupted bomb masses of $10^{3} \mathrm{~kg}$ and has ash-gas/bomb ratios of around one, and as high as two. There is no correlation between the quantity of bombs and quantity of gas-ash erupted. In addition, while source pressure for each explosion correlates with the quantity of gas and ash erupted, the mass of bombs emitted varies independently of pressure.
\end{abstract}

(c) 2013 Elsevier B.V. All rights reserved.

\section{Introduction}

Normal explosive eruptions at Stromboli volcano (Aeolian Islands, Italy) typically involve ejection of a mixed plume of gas, ash and bombs (e.g., Chouet et al., 1974; Ripepe et al., 1993; Patrick et al., 2007). The generally accepted model to explain this activity is the repeated ascent of large gas bubbles, or slugs, that burst at the free surface of the magma column (e.g., Blackburn et al., 1976; Jaupart and Vergniolle, 1988; Parfitt and Wilson, 1995). Bursting generates a cloud of bombs, ash and gas which ascends the empty section of the conduit to be released at the vent as an eruption plume (e.g., Jaupart and Vergniolle, 1989; Ripepe et al., 2001, 2002). The ensuing emission comprises two components: the first comprises bomb sized fragments which follow ballistic trajectories; the second comprises a cloud of finer particles and gas whose ascent shows a gas thrust phase followed by buoyant ascent (Patrick et al., 2007).

\footnotetext{
* Corresponding author. Tel.: +1 330473346737 .

E-mail address: a.harris@opgc.univ-bpclermont.fr (A.J.L. Harris).
}

The mass and volume of both gas and solid particles ejected during a single explosion, as well as their relative proportions, is a critical yet illusive measurement. It is a crucial parameter to have in hand if we are to fully parameterize and classify a Strombolian explosion (e.g., Walker, 1973; Chouet et al., 1974; Blackburn et al., 1976), as well as to understand and model the explosion mechanism that feeds the eruption (e.g., Parfitt and Wilson, 1995; Vergniolle et al., 1996; Parfitt, 2004). Modeling the ascent and dispersion dynamics of bomb-loaded plumes also requires knowledge of the particle size and number, as well as the mass of both the gaseous and solid components (e.g., Wilson and Self, 1980; Fagents and Wilson, 1993; Capaccioni and Cuccoli, 2005). System mass balance studies aimed at constraining the imbalance between degassed and erupted masses, by definition, also require reliable measurements of both degassed and erupted masses (e.g., Francis et al., 1993; Allard et al., 1994; Harris and Stevenson, 1997a). The problem is, Strombolian eruptions are typically characterized by repeated explosive emissions of unpredictable eruption interval that emit centimeter-to-meter sized particles, which are defined as bombs if they attain a diameter of greater than $6.4 \mathrm{~cm}$ (Cas and Wright, 1987). These land in a discontinuous 
Table 1

Published values for mass (in $\mathrm{kg}$ ) ejected during normal explosions at Stromboli. Summary results from this study combined the data for eruptions from the SW crater ( 3 eruptions) and the NE1 vent of the NE Crater (16 eruptions) as given in Appendix B.

\begin{tabular}{llccrr}
\hline & $\begin{array}{l}\text { Chouet } \\
\text { et al. (1974) }\end{array}$ & $\begin{array}{l}\text { Blackburn } \\
\text { et al. (1976) }\end{array}$ & $\begin{array}{l}\text { Ripepe } \\
\text { et al. (1993) }\end{array}$ & $\begin{array}{l}\text { Patrick } \\
(2005)\end{array}$ & This study \\
\hline No. & 2 & 8 & 10 & 344 & 19 \\
$\begin{array}{l}\text { Ejected Mass (kg) } \\
\text { Min. }\end{array}$ & & & & \\
Mean & - & 16 & 210 & 0 & 900 \\
Max. & 100 & 1230 & 6250 & 500 & 9600 \\
\hline
\end{tabular}

field close to the vent, making approach of the deposit for field measurement and sample return (for mass and volume constraint of the solid component of the emission) a difficult task.

Close approach to the vent, where the bomb field lies, is certainly a dangerous undertaking due to the risk of collector-impact during the next explosion. Vents are also often located within steep-sided pit craters, making them inaccessible. As a result, our understanding of the mass of solid particles ejected during an individual eruption has relied on remote sensing data. These data have typically been provided by ground-based cameras operating at high spatial resolutions and frame rates. Those rare measurements for masses of individual Strombolian explosions that exist have tended to use visible to near infrared camera stills to obtain the mass of all particles during flight (Chouet et al., 1974; Blackburn et al., 1976; Ripepe et al., 1993), with all three of these studies targeting normal explosive emissions at Stromboli. These results are collated in Table 1 and together yield data for 20 eruptions. Later, Patrick (2005) used thermal video to estimate the mass of all particles during flight. The technique of Patrick (2005) used the area of high temperature particles observed in sequential image stills and applied a shape assumption to obtain the volume of the particles. However, the measurement suffered from problems of double counting and thus gave an estimate of the bomb mass from the maximum value obtained from any single still obtained during the video sequence for the entire emission. We here present a new method for estimating bomb field mass which uses thermal infrared image data for the static, cooling bomb field. We present results for a further 32 eruptions, thereby doubling the amount of data available for studying and modeling the dynamics of Strombolian eruptions.

\section{Experiment location and set-up}

Stromboli is well known for its persistent mildly explosive style of activity that has likely been more or less continuous since between the third and seventh centuries AD (Rosi et al., 2000). Normal activity at Stromboli is characterized by repeated explosive events lasting a few seconds to tens of seconds and involves emission of jets and bursts of gas, ash and incandescent magma fragments to heights of between $100 \mathrm{~m}$ and $200 \mathrm{~m}$ (Barberi et al., 1993). Eruption frequencies are variable, but have a typical (time-averaged) rate of $\sim 9$ events/h (Harris and Ripepe, 2007). Activity has been localized at three main craters at least since 1776 when Stromboli was visited by Hamilton (Washington, 1917). The three craters (SW, Central and NE) are located at an elevation of $\sim 800 \mathrm{~m}$ and, together, have a SW-NE dimension of $\sim 250 \mathrm{~m}$. Bomb-sized particles follow ballistic trajectories to land within the crater zone, typically landing no more than $100 \mathrm{~m}$ from the vent. The reliability of explosive activity, and the relatively safe viewing from distances as close as $250 \mathrm{~m}$, has made Stromboli a popular target for measurements that seek to parameterize and understand the dynamics of the emissions associated with such explosive activity (e.g., Chouet et al., 1974; Ripepe et al., 1993; Patrick et al., 2007).

We deployed a thermal video camera to measure the temperature of individual bombs within cooling bomb fields between 30 May and 8 June 2008, as well as on 1 June 2010, during a period of typical, normal, explosive activity. The camera used was a FLIR systems S40 which collects $320 \times 240$ pixel images in the thermal infrared $(7.5-13 \mu \mathrm{m})$, with each pixel having an instantaneous field of view (IFOV) defined by an angle of $1.3 \mathrm{mrad}$. We collected imagery via a fire-wire connection to a laptop at frame rates of $7.5 \mathrm{~Hz}$ using the camera's mid-range gain setting. This allows measurement of pixel-integrated temperatures in the range $0-500{ }^{\circ} \mathrm{C}$. Upon landing, bomb exteriors had cooled to such an extent that no saturation was experienced using this range, pixel-integrated temperatures for bomb-containing pixels typically being in the range $90-190{ }^{\circ} \mathrm{C}$. Temperatures were corrected for emissivity and atmospheric effects using the camera's onboard (MODTRAN-based) software and inputting measurements of air temperature and humidity, obtained at the measurement site every $15 \mathrm{~min}$. The camera was pointed not at the sky above the vent to capture the plume ascent, but at a zone below the vent in which the bombs fell; thus allowing data for the size, area and cooling properties of the bomb field to be estimated. However, because the plume was not imaged, no information regarding the plume dynamics could be extracted from this imagery.

During June 2008 a vent active within the SW crater was targeted from Pizzo Sopra la Fossa. The vent was visible on the crater floor, meaning that the entire bomb field was imaged as it cooled (Fig. 1a and b). The line-of-sight distance $\left(D_{L O S}\right)$ to the vent (as measured with a laser range finder) was $227 \mathrm{~m}$, with the camera being tilted downwards at an angle of $25^{\circ}$. Oblique viewing will induce pixel distortion. Pixel dimension $\left(D_{\text {pixel }}\right)$ for surface orientated at rightangles to the camera can be estimated from the simple geometric relation $D_{\text {pixel }}=2\left[D_{\text {LOS }} \tan (\right.$ IFOV) $)$. However, viewed at a downward pointing angle of $\theta$, the adjusted pixel dimension $\left(D_{\text {adjust }}\right)$ will be $D_{\text {pixel }} / \sin (\theta)$ for a flat surface or $D_{\text {pixel }} / \sin (\beta)$ for a vertical surface, $\beta$ being 90 minus $\theta$. Thus, for our case we have square pixel area of $0.09,0.49$ and $0.11 \mathrm{~m}^{2}$ for the three cases, respectively. During June 2008 two vents active within the NE crater were targeted (Fig. 1c and d). The crater was shallow and emissions from one of the vents (NE1) were directed towards the camera site so that most, if not all, of the bomb field was imaged as it cooled (Fig. 1d). The line-of-sight distance to the vent was $400 \mathrm{~m}$, with the camera being positioned so that the surface was orientated more or less at right-angles in respect to the image plane, so that the pixel area at the bomb field was $0.27 \mathrm{~m}^{2}$.

A second camera, permanently located at a site $\sim 500 \mathrm{~m}$ NE of the active craters, was used to extract the dynamic properties of the ascending cloud (velocity, volume flux and maximum temperature). This camera was a FLIR A20, which collects $160 \times 120$ pixel images and is sensitive in the $7.5-13 \mu \mathrm{m}$ waveband. Images were transmitted to a reception site on the island where they were processed and archived 5 times a second, giving a frame rate of $5 \mathrm{~Hz}$. The A20 camera targeted the plumes as they ascended above the vent, but not the bomb field. Thus the two cameras, permanent and temporary, were used to extract information regarding the ascending plume and its associated bomb field, respectively. All camera specifications, location and line of sight details are given in Appendix A.

\section{Method}

\subsection{Total bomb mass from bomb field power loss}

Radiative and convective power flux densities ( $q_{\text {rad }}$ and $q_{\text {conv }}$, in $\mathrm{W} \mathrm{m}^{-2}$ ) for a hot particle at temperature $T$ can be obtained 
from

$q_{\text {rad }}=\varepsilon \sigma\left(T^{4}-T_{0}^{4}\right)$

$q_{\text {conv }}=h_{c}\left(T-T_{0}\right)$

in which $\varepsilon$ is emissivity, $\sigma$ is the Stefan-Boltzmann constant $\left(5.67 \times 10^{-8} \mathrm{~W} \mathrm{~m}^{-2} \mathrm{~K}^{-4}\right), T_{0}$ is ambient temperature and $h_{c}$ is the convective heat transfer coefficient. Multiplying by area $(A)$ yields the radiative and convective power fluxes $\left(\Phi_{\text {rad }}\right.$ and $\Phi_{c o n v}$, in $\mathrm{J} \mathrm{s}^{-1}$ ), i.e.,

$\Phi_{\text {rad }}=\varepsilon \sigma\left(T^{4}-T_{0}^{4}\right) A$

$\Phi_{\text {conv }}=h_{c}\left(T-T_{0}\right) A$

The thermal video data (from the camera targeting the bomb field) can be used to estimate the temperature of individual bombs at $0.133 \mathrm{~s}$ time intervals, and hence used to solve Eq. (1) and (2). Plotting bomb temperature through time yields the cooling curve for the bomb (Fig. 2a). Due to atmospheric and gas effects, the curve is somewhat noisy. We thus smooth the curve using the maximum temperature obtained over a 30 second-long moving time window. The smoothed temperature curve can now be converted, using Eqs. (2a) and (2b) with appropriate constants, to radiative and convective power fluxes (Fig. 2b). To do this we select pixel-filling bombs so that $A$ is given by the pixel area, and solve using an 8-14 $\mu \mathrm{m}$ emissivity of 0.956 obtained for Stromboli's bombs by Harris and Stevenson (1997b) and a convective heat transfer coefficient of $50 \mathrm{~W} \mathrm{~m}^{-2} \mathrm{~K}^{-1}$ from Keszthelyi et al. (2003). For cases where cooling of the bomb could not be tracked through to ambient, we used the best-fit curves obtained from the cooling curves, as given in Electronic Supplement Table 1, to project the cooling curve to ambient (i.e., the point at which the bomb cools to $T_{0}$ ); thereby allowing us to obtain an estimation for the power flux during cooling to ambient.
If we integrate the power fluxes through time, we obtain the total energy released by the bomb ( $E$ in Joules) in cooling from its emplacement temperature $\left(T_{e}\right)$ to ambient $\left(T_{0}\right)$. Such an approach was applied, using thermal data collected by the ATSR satellitesensor, by Wooster et al. (1997) to obtain the energy released by cooling lava during Etna's 1991-1993 lava flow field. This can now be used to estimate the mass of lava $(M$, in $\mathrm{kg}$ ) required to generate the measured energy (Yokoyama, 1957):

$M=\frac{E}{c_{p}\left(T_{e}-T_{0}\right)}$

in which $c_{p}$ is the specific heat capacity. Multiplying the bottom line by density allows Eq. (3a) to be expressed in terms of volume $(V)$ :

$V=\frac{E}{\rho c_{p}\left(T_{e}-T_{0}\right)}$

Term $c_{p}\left(T_{e}-T_{0}\right)$ defines the power (in Joules) generated per kilogram of bomb in cooling from its starting temperature $\left(T_{e}\right)$ to ambient $\left(T_{0}\right)$. The starting temperature $\left(T_{e}\right)$ will be the bomb eruption or interior temperature, rather than its surface temperature $\left(T_{\text {surf }}\right)$, so that $T_{e}>T_{\text {surf. }}$ Thus, $M c_{p}\left(T_{e}-T_{0}\right)$ defines the total power, in Joules, available in cooling the entire bomb from its molten state. In other words, the bomb will emit (lose) all of that power in cooling from $T_{e}$ to $T_{0}$. Thus, the time integral of each power flux curve must equal the total power available, i.e., $M c_{p}\left(T_{e}-T_{0}\right)$. Initial applications of this equation in volcanology used the total mass or volume of erupted products to estimate lava and ejecta heat budgets (e.g., Verhoogen, 1946; Yokoyama, 1957; Hérdervári, 1963; Friedman and Williams, 1968; Scandone, 1979). Recently, the approach has been inverted, and power fluxes (derived from satellite-sensor cooling curves) have been integrated through time to yield total energy released by cooling lava, which is then converted to lava flow volume (Rowland et al., 2003; Ganci et al., in press; Gouhier et al., in press).
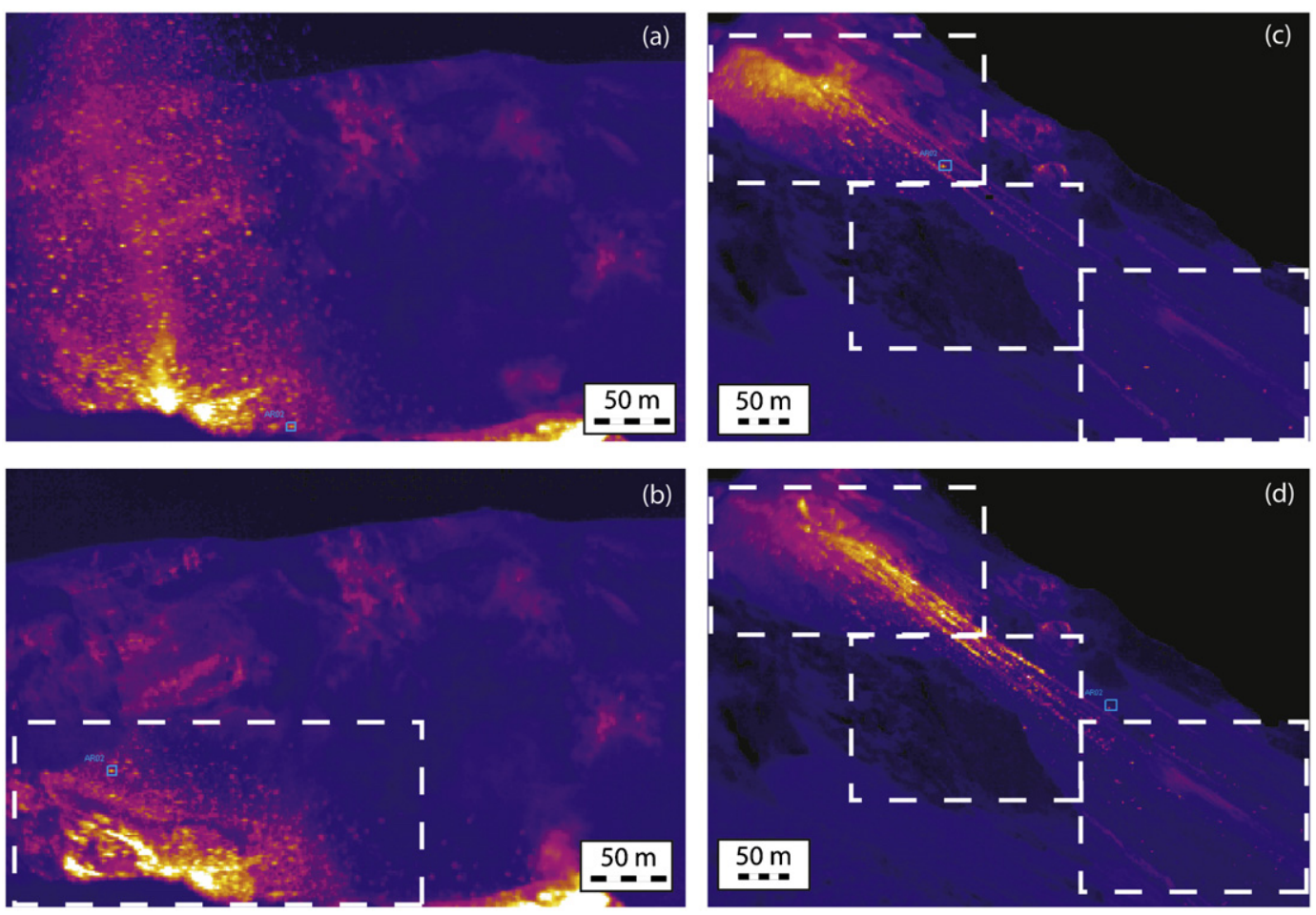

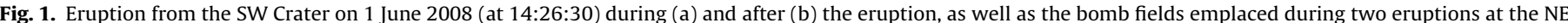

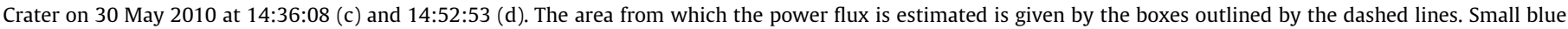
boxes locate "control" bombs selected for this eruption (see Section 4.1). 

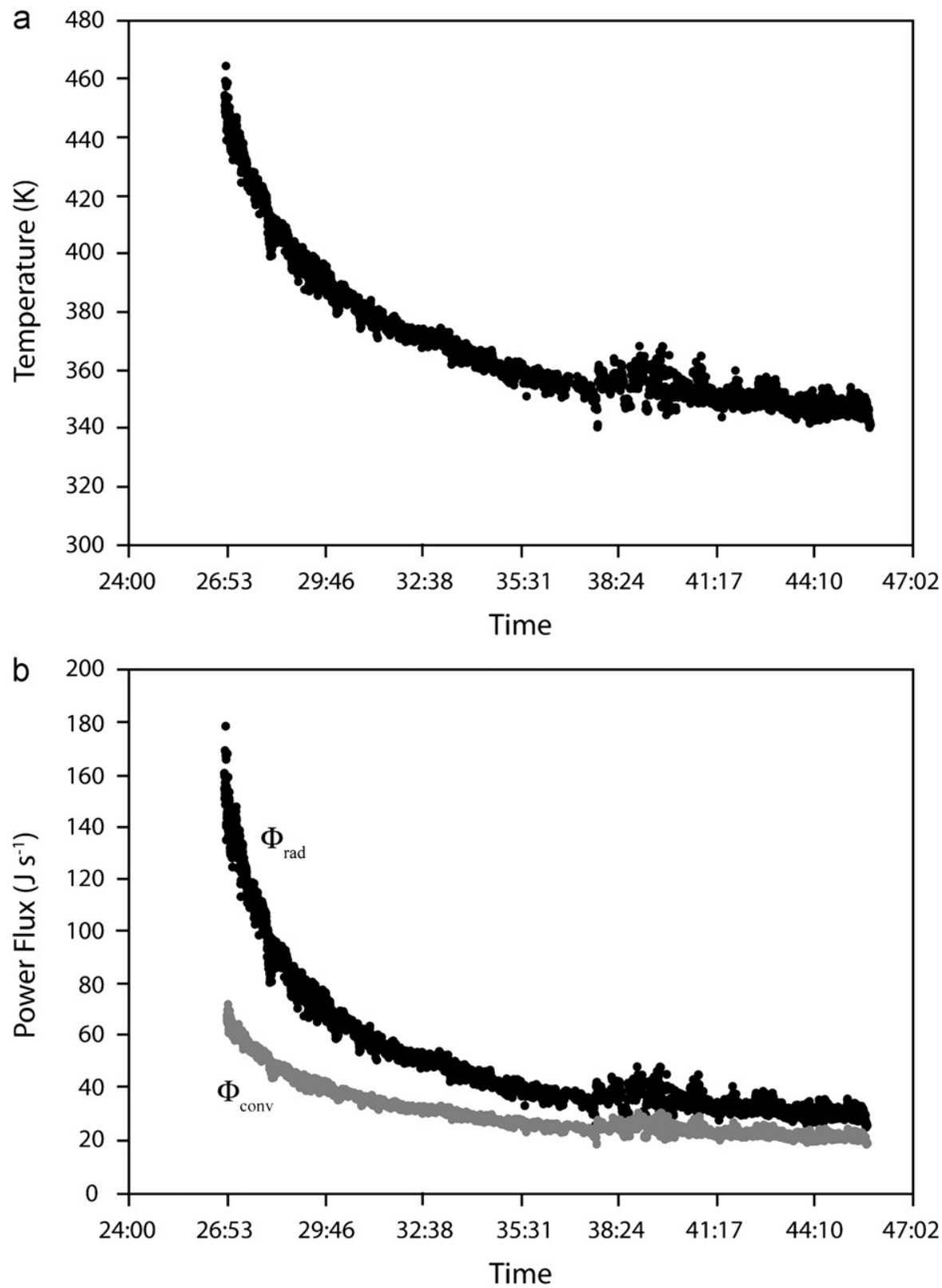

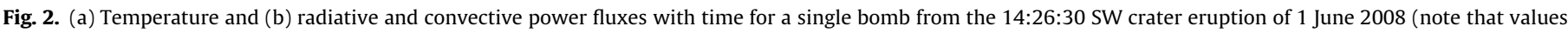
for $\Phi_{\text {conv }}$ have been divided by 10 ).

We calculate a density value for Stromboli's magma of $2740 \mathrm{~kg} \mathrm{~m}^{-3}$ using the chemistry for Stromboli's scoria given by Cigolini et al. (2008) in the method of Bottinga and Weill (1970). We convert this to a bulk density using the typical vesicularities for high density bombs at Stromboli, this being 45\% (from Lautze and Houghton (2007)). This yields a bulk density of $1230 \mathrm{~kg} \mathrm{~m}^{-3}$. This vesicularity $(\varpi)$ can also be used in the relation of Peck (1978) to estimate the specific heat capacity for vesicular basalt $\left[c_{p}=(1.929-1.554 \times \varpi)^{2} \times 1000\right]$, a relation that yields, for our case, a $c_{p}$ of $1510 \mathrm{~J} \mathrm{~kg}^{-1} \mathrm{~K}^{-1}$. Using these values in Eqs. (3a) and (3b) now allows us to solve for individual bomb mass or volume.

If we take the total energy released by all bombs in the field, which we can use to solve for the total mass or volume of bombs emitted during the explosion. To do this, we take the total area of the bomb field (i.e., all pixels above a temperature threshold that separates hot bomb pixels from the cooler ground onto which they fell). We then use the maximum temperature and maximum minus one standard deviation temperature from the field during each time step to place upper and lower bounds on the power fluxes. We use the maximum temperature because this is most likely to represent a 'pure' temperature of a pixel-filling bomb. If we use the pixel-integrated temperature for a pixel containing a hot bomb that is smaller than the pixel, the pixel-integrated temperature will be less than the actual bomb temperature; hence power fluxes will be under-estimated. We recognize, though, that not all bombs may have the same temperature, thus we calculate a parameter range using the maximum minus one standard deviation temperature as a lower bound. The extracted bomb field power fluxes are then integrated through time to give upper and lower bounds on the likely mass and volume of ejecta responsible for the derived bomb field energy value. We continue the integration until the power flux curve reaches its preexplosion level (Fig. 3), and solve Eq (3) assuming that the bomb interior cools from a starting temperature of $1000{ }^{\circ} \mathrm{C}$ to an ambient temperature of $25^{\circ} \mathrm{C}$. Overestimate may result from 


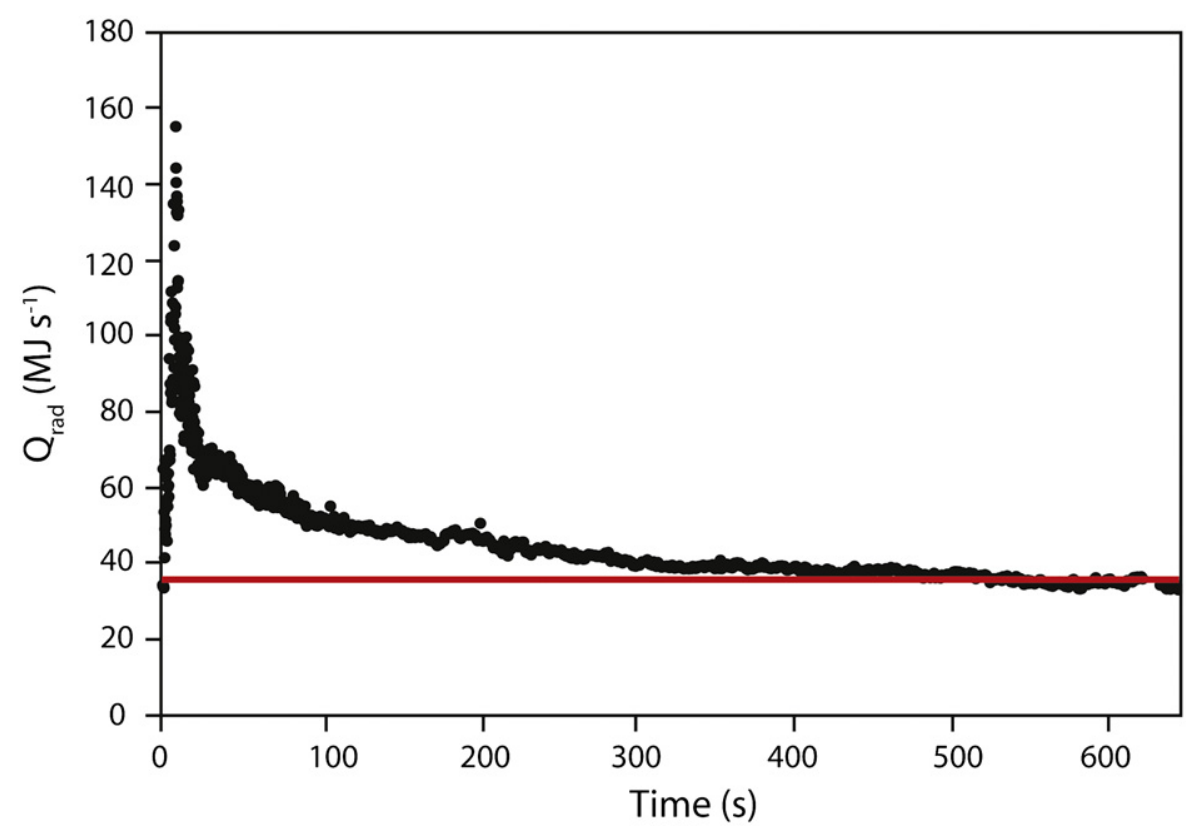

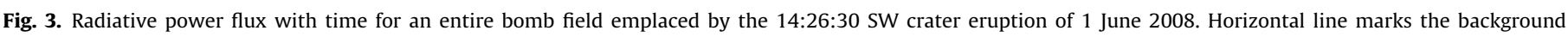
(ambient) heat flux level.

the consideration of heat sources not related to the bomb field in question (i.e., hot vents and still cooling bombs from previous eruptions). However, bombs from previous events are not apparent in our imagery, with the power flux curves descending to background levels within $400 \mathrm{~s}$ of the event (Fig. 3). For our SW Crater estimates a $2.5 \mathrm{~m}$ wide $\left(4.6 \mathrm{~m}^{2}\right)$ vent at $\sim 500{ }^{\circ} \mathrm{C}$ was located within the image. The presence of such a source would contribute $\sim 9.3 \times 10^{4} \mathrm{~J} \mathrm{~s}^{-1}$ to the radiative power flux, adding (over $300 \mathrm{~s}-320 \mathrm{~s}$ ) an extra $\sim 0.035 \mathrm{GJ}$. This compares with a radiative power flux of between $3 \mathrm{GJ}$ and $5 \mathrm{GJ}$ obtained for the SW Crater bomb fields (see Electronic Supplement Table 3), so that its inclusion causes an over-estimate of the bomb mass by just $\sim 0.25 \%$. This error is lost in rounding.

\subsection{Emission velocity, plume volume flux, volume and temperature}

The at-vent plume velocity for each eruption was obtained from the permanent camera video data. This was achieved by plotting the temperature contours across the plume, and then comparing the difference in position of each contour between each image (Delle Donne and Ripepe, 2012). This gives the distance moved $(\Delta d)$ by each contour over a known timeinterval $(\Delta t)$, i.e., the difference in time between each image acquisition, so that the velocity at which each contour propagates $(u)$ is obtained from $\Delta d / \Delta t$. The maximum velocity obtained for each image was saved, this being the at-vent velocity. The at-vent plume propagation velocity was then multiplied by the vent area $\left(A_{v e n t}\right)$ to obtain the volume flux of all material (all components: gas, ash and bombs) passing through the vent. As is typical of vents at Stromboli, the vent was roughly circular, with a radius of $2 \mathrm{~m}$ and an area of $12.6 \mathrm{~m}^{2}$. Integrating the entire plume volume flux through time yields the total volume of all components erupted during each event. To isolate the volume of just the gas and ash component, we subtracted the bomb volume as calculated from the bomb field cooling data. Finally, the volume of the gas and ash component was converted to a mass using a density between 0.35 and $1.15 \mathrm{~kg} \mathrm{~m}^{-3}$. The former density is for steam at $650 \mathrm{~K}$, and so is appropriate for an ash-free plume of pure gas. The latter density is the maximum possible density if the mixture of gas and ash is to remain buoyant (i.e., it is just a little less than the density of air at $300 \mathrm{~K}$, which is $1.18 \mathrm{~kg} \mathrm{~m}^{-3}$ ). This approximates the gas density range of $0.25-1.2 \mathrm{~kg} \mathrm{~m}^{-3}$ obtained for normal explosive plumes at Stromboli by Patrick (2007).

\section{Results}

\subsection{Bomb cooling and bomb field mass}

We tested the approach on eight individual bombs from eight different eruptions (three SW Crater eruptions in June 2008, and five NE Crater eruptions in May-June 2010). All cooling curves could be best fit by an exponential decay, with $R^{2}$ typically greater than $\sim 0.8$ (all bomb cooling curve and total energy derivations are given in Electronic Supplement Table 1). Such an exponential decay in surface temperature is to be expected given cooling subject to heat loss by radiation, and mimics the form of cooling curves obtained for lava flow surfaces (e.g., Hon et al., 1994; Harris et al., 2007). However, it is somewhat complicated by bomb vesiculation, expansion and "popping", where the bomb expands to such an extent that it explodes, an effect which can be observed in the imagery: expansion of the bomb causes the surface to tear, crack and rupture, exposing the hotter interior and causing a temporary reversal of the cooling trend.

Total energy released by individual bombs during cooling ranged from $0.2 \mathrm{MJ}$ to $1.3 \mathrm{MJ}$. These translated to masses for individual bombs of between $6 \mathrm{~kg}$ and $9 \mathrm{~kg}$ for the NE Crater data set. The bombs selected from the SW Crater events give somewhat lower masses of $1 \mathrm{~kg}, 1.4 \mathrm{~kg}$ and $2.5 \mathrm{~kg}$ (all bomb mass, volume and dimension conversions are given in Electronic Supplement Table 2). If we assume a spherical shape for the bomb, the volumes for the NE Crater bombs convert to typical bomb diameters of between $21 \mathrm{~cm}$ and $24 \mathrm{~cm}$. Those of the SW crater bombs convert to diameters of $12-16 \mathrm{~cm}$. Field measurements of 37 bombs that managed to escape the SW Crater, and that we found at a distance of between $160 \mathrm{~m}$ and $250 \mathrm{~m}$ from the vent, revealed typical diameters (for bombs with approximately circular plan views) of $12 \mathrm{~cm}$ to $28 \mathrm{~cm}$ (mean $=21 \mathrm{~cm}$ ). These were not the same bombs as those imaged (approach of these was unsafe), but were collected from safe areas to serve as a proxy for 
the explosions that were imaged. Our image-derived results thus appear plausible. However, only $14 \%$ of the bombs examined in the field were circular, the remainder being elongate with long axes that ranged from $23 \mathrm{~cm}$ to $150 \mathrm{~cm}$ in length (mean $=63 \mathrm{~cm}$ ). Such bombs would extend across the entire width of our $30 \mathrm{~cm}$ (SW Crater) to $52 \mathrm{~cm}$ (NE Crater) pixels. Thus we also calculate bomb dimensions using an elongate bomb model, with a long axis extending the entire width of the pixel and a thickness of $5 \mathrm{~cm}$ (typical of the field-measured bombs). These results are given as dimension 2 (elongate) in Electronic Supplement Table 2 and indicate median axis lengths in the range $7-27 \mathrm{~cm}$. These compare with field measured median axis lengths of $11-60 \mathrm{~cm}$ $($ mean $=28 \mathrm{~cm})$. Theoretical heat flux decay curves, obtained using these volumes and dimensions with the Stefan cooling calculations, show good fits with the measured curves, if bomb interior temperature is adjusted appropriately (see Electronic Supplement 1).

We next applied the method to the entire bomb fields for the same eight eruptions. Again, all power flux decay curves showed an exponentially decaying trend, with power fluxes returning to pre-explosion levels within 300-400 s (e.g., Fig. 3). Total energy released by the entire bomb field during cooling ranged from $13 \mathrm{MJ}$ to $51 \mathrm{MJ}$. These translated to bomb field masses of between $9 \times 10^{3} \mathrm{~kg}$ and $11 \times 10^{3} \mathrm{~kg}$ for the three SW Crater bomb fields, and $21 \times 10^{3} \mathrm{~kg}$ to $35 \times 10^{3} \mathrm{~kg}$ for the NE Crater data set (all results are given in Electronic Supplement Table 3, and summarized in Table 2). If we take the typical mass of the SW Crater bomb fields $\left(9.75 \times 10^{3} \mathrm{~kg}\right)$ and divide by the typical mass for an individual bomb $(2.5 \mathrm{~kg})$, we obtain 3900 particles. For the NE Crater bomb fields, the typical field mass $\left(26.6 \times 10^{3} \mathrm{~kg}\right)$ and individual bomb mass ( $7 \mathrm{~kg}$ ) yields 3800 particles. This compares with 2594 particles counted in one eruption by Chouet et al. (1974).

We cross-checked these values with a geometrically derived value for the bomb field volume. To do this we took the area of the bomb field at the time when the final bomb landed. We multiplied this area by the typical particle thickness found by Chouet et al. (1974), i.e., $2.2 \mathrm{~cm}$, and the typical bomb thickness obtained from our field survey $(5 \mathrm{~cm})$. Note that area of the bomb field is the summed area of individual bombs, not the encompassing area around all the bombs. These bulk volumes were corrected for a vesicularity of $45 \%$ (results are given in Electronic Supplement Table 4). We find good agreement with the thermally-derived volumes for the SW Crater, with the thermally-derived volumes spanning a much reduced range, which falls within (or towards the bottom end of) the geometrically-derived dense rock volume range (see Electronic Supplement Table 4). This is expected due to the geometricallyderived ranges being over-estimates, a result of our setting pixel area equal to bomb area when the bombs will likely be of subpixel size. We thus trust our thermally-derived volumes more than the geometrically-derived volumes, but are happy that the two independently derived values are in agreement and that thermally-derived volumes are typically a little lower.

Total bomb field energies, as well as the derived volumes and masses for all bombs erupted for each of the 32 events recorded by us are given in Appendix B. We note that, for eruptions from vent NE2, not all of the erupted bombs escaped the crater, so that our NE2 estimates place a minimum bound on the actual value. However, emissions from NE1 were directed towards the camera so that the imaged bomb field includes most, if not all, of the bombs erupted (see Fig. 1c and d). Likewise, all bombs erupted during the three SW crater events recorded in 2008 rose and fell within the crater to form a bomb field tightly clustered around the vent. Our view down into the SW crater meant that most of these bombs were imaged, although some bombs falling to the left of our image may have been missed (see Fig. 1a and b).

\subsection{Plume volume and mass}

From the location of the permanent camera, only eruptions at the NE Crater are visible. Thus, in Appendix C, maximum plume velocity and plume volume for just the NE crater eruptions of Appendix B are given. Values derived from combining the data in Appendices B and C, i.e., volume and mass of the gas-ash component, plus the gas-ash to bombs ratio, are given in Appendix D. The volume of the gas--ash component of each emission is much higher than that of bomb component, having a typical volume of $\sim 1350 \mathrm{~m}^{3}$ (Appendix D). This compares with a range of $10^{3}-10^{4} \mathrm{~m}^{3}$ obtained for the gas-ash component mixture at Stromboli during normal activity by Delle Donne and Ripepe (2012), and with $\sim 5 \mathrm{~m}^{3}$ of bombs per eruption obtained here (Appendix B). In terms of masses, we derived typical values for the gas-ash component of $\sim 470 \mathrm{~kg}$, if the plume is just composed of gas, or $1550 \mathrm{~kg}$, if the plume is a mix of buoyant ash and gas (Appendix D). Maximum plume masses are around $3460 \mathrm{~kg}$, but can be as low as $\sim 100 \mathrm{~kg}$; thus varying over two-orders of magnitude.

\section{Discussion}

\subsection{Bomb masses ejected during normal explosions at Stromboli}

If we consider all events listed in Appendix B, our method yields a typical bomb mass erupted during a single normal explosive event at Stromboli as $\sim 6 \times 10^{3} \mathrm{~kg}$. However, examination of the thermal video data reveals that a portion of the bombs from NE2 eruptions fell back into the crater and were thus hidden from our view. In Table 2 we tabulate the bomb mass extractions for just the NE1 eruptions. These emissions were directed towards our camera; examination of the thermal video data shows that most of the bombs escaped the crater to be emplaced in a bomb field extending in an elongate zone extending down the outer flank of the crater exposed to our camera view. For these eruptions, we are thus confident that we have captured all of the bombs. If we consider just these eruptions, the average erupted bomb mass increases to $\sim 10^{4} \mathrm{~kg}$ (Table 2). Likewise the SW Crater eruptions of 2008 yielded a typical erupted bomb mass approaching $10^{4} \mathrm{~kg}$ (Appendix B).

Compared with previous estimates for the mass of bombs ejected during normal explosions at Stromboli, our method gives a result that is a little higher (Table 1 ), being $\sim 10^{4} \mathrm{~kg}$ as opposed to $\sim 10^{3} \mathrm{~kg}$ given by Blackburn et al. (1976), $\sim 6 \times 10^{3} \mathrm{~kg}$ given by Ripepe et al. (1993) and $1-3 \times 10^{3} \mathrm{~kg}$ given by Calvari et al. (2012). These results are, in turn, much higher than the estimates of $10 \mathrm{~kg}$ and $100 \mathrm{~kg}$ for the two eruptions of Chouet et al. (1974). Some of the difference may result from previous estimates using the maximum value approach to avoid double counting, whereby the largest mass recorded in any single frame acquired during the emission is assumed to approximate the total mass ejected during the entire eruption. Ripepe et al. (1993) show that this assumption holds if the material is ejected in a short single burst, but will result in underestimate if material is ejected in a multiple bursts, where many events at Stromboli are actually multiple-burst (Harris and Ripepe, 2007). By taking the power flux from the entire bomb field, our approach considers every bomb ejected during the event, in all bursts. It thus seems that a more likely value for the mass emitted by normal explosive events at Stromboli is of the order of $10^{3}-10^{4} \mathrm{~kg}$. This range is a little lower than values estimated for stronger ("major") explosions at 
Stromboli, with masses of $7.5 \times 10^{4} \mathrm{~kg}$ and $\sim 2 \times 10^{4} \mathrm{~kg}$ being obtained for major eruptions on 7 September 2008 (Calvari et al., 2012) and 21 January 2010 (Gurioli et al., in press), and much lower than masses of $1.1-1.4 \times 10^{8} \mathrm{~kg}$ estimated for Stromboli's 5 April 2003 paroxysm (Rosi et al., 2006).

Ripepe et al. (1993) give masses for bombs ejected during explosions at Stromboli for six eruptions in 1988 and 1989. These yield a range of $0.2 \times 10^{3}-4.4 \times 10^{3} \mathrm{~kg}$, with a mean of $2.2 \times 10^{3} \mathrm{~kg}$. This is similar to the results of Blackburn et al. (1976). However, Ripepe et al. (1993) also give masses for four explosions during 1991, these yield a range of $0.8 \times 10^{3}-$ $32 \times 10^{3} \mathrm{~kg}$, with the two largest eruptions having masses of $1.3 \times 10^{4} \mathrm{~kg}$ and $3.2 \times 10^{4} \mathrm{~kg}$. The masses for the two largest events of Ripepe et al. (1993) are almost identical to our range of $2.1 \times 10^{4}-3.5 \times 10^{4} \mathrm{~kg}$ obtained for our explosions of 30 May 2010 (Table 2). Thus, eruptions emitting bomb masses of $\sim 10^{4} \mathrm{~kg}$ do not seem to be out of the ordinary at Stromboli during normal activity. Erupted bomb masses do, though, vary from eruption-toeruption and from day-to-day. In Table 2, for example, we see typical erupted bomb masses of $\sim 27 \times 10^{3} \mathrm{~kg}$ on 30 May, but $\sim 2 \times 10^{3} \mathrm{~kg}$ by 2 June. Again these ranges sit nicely within those obtained by previous studies, lending further confidence to the results of our thermal methodology.

\subsection{Gas-ash masses and volumes ejected during normal explosions} at Stromboli

In Table 2a the gas-ash masses for the NE1 eruptions are also given, along with the ratio of the gas-ash component to the bomb component. The ratios are highly variable. The lowest ratio is 0.01 , meaning that, in terms of mass, the emission was bomb dominated with just $1 \%$ of the emission comprising gas and ash. This is typical of the eruptions recorded on 30 May 2010 (Table 2a). The highest ratios recorded in Table 2a approach two, meaning that there was twice as much gas and ash as bombs. In these cases, the gas and ash component can comprise up to $70 \%$ of the emission by mass. This was the case for most of the eruptions recorded on 2 May (Table 2a). Thus, the normal explosive emissions can toggle between two eruption types defined by their characteristic mass loadings and component ratios. The first type is bomb-dominated. These are characterized by bomb masses of $10^{4} \mathrm{~kg}$ and ash-gas/ bomb ratios of $\sim 0.02$. These are the Type 1 eruptions of Patrick et al. (2007), which are dominated by coarse ballistic particles. Our second type is ash-and-gas dominated. These are characterized by erupted bomb masses of $10^{3} \mathrm{~kg}$ and ash-gas/bomb ratios of around one, and as high as two. In such eruptions, the ash-gas component thus at-least matches the bomb component by mass, and can exceed it. These are the Type 2 eruptions of Patrick et al. (2007), which consist of "an optically-thick, ash-rich plume, with (Type 2a) or without (Type 2b) large numbers of ballistic particles".

However, because of the very different densities of the gas-ash and bomb components of the cloud, by volume the results are very different, with the gas-ash component dominating (Table $2 \mathrm{~b}$ ). In terms of volume, there is typically $\sim 1000$ times more gas-ash than bombs, so that the gas-ash component makes up more than $96 \%$ of the emission by volume.

\subsection{Relation between gas overpressure, emission velocity, and plume component masses}

To understand the relation between the physical parameters driving the emission, we checked the correlation between bomb mass, gas-ash mass, source pressure (in terms of infrasonic amplitude and energy) and ejection velocity. We found the following:

- No correlation between erupted bomb mass and erupted gasash mass;

- No correlation between source pressure and erupted bomb mass;

- No correlation between source pressure and the mass ratio of bombs to gas-ash;

- No correlation between erupted bomb mass and ejection velocity;

However, we did find a correlation between:

- Source pressure and erupted gas-ash mass (positive and linear, Fig. 4b);

Table 2a

Bomb mass and gas-ash masses extracted for the NE1 vent eruptions of 2010.

\begin{tabular}{|c|c|c|c|c|c|c|c|}
\hline \multirow{2}{*}{$\begin{array}{l}\text { Date } \\
\text { (dd/mm/yy) }\end{array}$} & \multirow{2}{*}{$\begin{array}{l}\text { Time } \\
\text { (hh:mm:ss) }\end{array}$} & \multicolumn{2}{|c|}{$\begin{array}{l}\text { Bomb mass } \\
(\mathrm{kg})\end{array}$} & \multicolumn{2}{|c|}{$\begin{array}{l}\text { Gas-ash mass } \\
(\mathrm{kg})\end{array}$} & \multicolumn{2}{|c|}{$\begin{array}{l}\text { Gas-ash/bomb } \\
\text { (ratio) }\end{array}$} \\
\hline & & Min & Max & Min & Max & Min & Max \\
\hline $30 / 05 / 2010$ & $13: 32: 03$ & 21,400 & 24,300 & 316 & 1038 & 0.01 & 0.04 \\
\hline $30 / 05 / 2010$ & $13: 57: 39$ & 25,000 & 27,600 & No data & No data & No data & No data \\
\hline $30 / 05 / 2010$ & $14: 20: 57$ & 27,700 & 30,700 & No data & No data & No data & No data \\
\hline $30 / 05 / 2010$ & $14: 36: 08$ & 20,500 & 22,700 & 239 & 785 & 0.01 & 0.03 \\
\hline $30 / 05 / 2010$ & $14: 52: 53$ & 31,400 & 34,700 & 242 & 795 & 0.01 & 0.02 \\
\hline $02 / 06 / 2010$ & $11: 16: 52$ & 1200 & 1300 & No data & No data & No data & No data \\
\hline $02 / 06 / 2010$ & $11: 35: 23$ & 1100 & 1400 & No data & No data & No data & No data \\
\hline $02 / 06 / 2010$ & $11: 57: 51$ & 3500 & 3800 & 1054 & 3463 & 0.30 & 0.91 \\
\hline $02 / 06 / 2010$ & $12: 22: 35$ & 2700 & 3000 & 109 & 358 & 0.04 & 0.12 \\
\hline $02 / 06 / 2010$ & 14:08:51 & 1700 & 1800 & 939 & 3086 & 0.55 & 1.71 \\
\hline $02 / 06 / 2010$ & $14: 38: 43$ & 1700 & 1900 & 872 & 2864 & 0.51 & 1.51 \\
\hline $02 / 06 / 2010$ & $14: 59: 53$ & 3300 & 3700 & 1016 & 3337 & 0.31 & 0.90 \\
\hline $02 / 06 / 2010$ & $15: 48: 05$ & 1100 & 1200 & 800 & 2630 & 0.73 & 2.19 \\
\hline $02 / 06 / 2010$ & $16: 08: 17$ & 900 & 1000 & 574 & 1885 & 0.64 & 1.89 \\
\hline $02 / 06 / 2010$ & $16: 12: 11$ & 1300 & 1400 & 859 & 2822 & 0.66 & 2.02 \\
\hline $08 / 06 / 2010$ & $13: 50: 46$ & 1300 & 1400 & 451 & 1483 & 0.35 & 1.06 \\
\hline Min & & 900 & 1000 & 109 & 358 & 0.01 & 0.02 \\
\hline Max & & 31,400 & 34,700 & 1054 & 3463 & 0.73 & 2.19 \\
\hline Mean & & 9113 & 10,119 & 623 & 2045 & 0.34 & 1.03 \\
\hline St. Dev. & & 11,466 & 12,728 & 340 & 1117 & 0.28 & 0.83 \\
\hline
\end{tabular}


Table 2b

Bomb mass and gas-ash volumes extracted for the NE1 vent eruptions of 2010 , gas-ash (\%) is the percentage of the plume, by volume, comprising gas-ash.

\begin{tabular}{|c|c|c|c|c|c|}
\hline $\begin{array}{l}\text { Date } \\
\text { (dd/mm/yy) }\end{array}$ & $\begin{array}{l}\text { Time } \\
\text { (hh:mm:ss) }\end{array}$ & $\begin{array}{l}\text { Bomb volume } \\
\left(\mathrm{m}^{3}\right)\end{array}$ & $\begin{array}{l}\text { Ash-gas volume } \\
\left(\mathrm{m}^{3}\right)\end{array}$ & $\begin{array}{l}\text { Gas-ash/bomb } \\
\text { (ratio) }\end{array}$ & $\begin{array}{l}\text { Gas-ash } \\
(\%)\end{array}$ \\
\hline $30 / 05 / 2010$ & $13: 32: 03$ & 18.5 & 921 & 50 & 98.0 \\
\hline $30 / 05 / 2010$ & $13: 57: 39$ & 21.0 & No data & No data & No data \\
\hline $30 / 05 / 2010$ & $14: 20: 57$ & 23.5 & No data & No data & No data \\
\hline $30 / 05 / 2010$ & $14: 36: 08$ & 17.5 & 700 & 40 & 97.6 \\
\hline $30 / 05 / 2010$ & $14: 52: 53$ & 27.0 & 718 & 27 & 96.4 \\
\hline $02 / 06 / 2010$ & $11: 16: 52$ & 1.0 & No data & No data & No data \\
\hline $02 / 06 / 2010$ & $11: 35: 23$ & 1.4 & 287 & 213 & 99.5 \\
\hline $02 / 06 / 2010$ & $11: 57: 51$ & 3.0 & 3014 & 1022 & 99.9 \\
\hline $02 / 06 / 2010$ & $12: 22: 35$ & 2.3 & 313 & 136 & 99.3 \\
\hline $02 / 06 / 2010$ & $14: 08: 51$ & 1.4 & 2685 & 1918 & 99.9 \\
\hline $02 / 06 / 2010$ & $14: 38: 43$ & 1.5 & 2492 & 1718 & 99.9 \\
\hline $02 / 06 / 2010$ & $14: 59: 53$ & 2.9 & 2904 & 1019 & 99.9 \\
\hline $02 / 06 / 2010$ & $15: 48: 05$ & 0.9 & 2288 & 2542 & 100.0 \\
\hline $02 / 06 / 2010$ & $16: 08: 17$ & 0.8 & 1640 & 2187 & 100.0 \\
\hline $02 / 06 / 2010$ & $16: 12: 11$ & 1.1 & 2455 & 2338 & 100.0 \\
\hline $08 / 06 / 2010$ & $13: 50: 46$ & 1.1 & 1290 & 1229 & 99.9 \\
\hline Min & & 0.8 & 287.3 & 27 & 96.4 \\
\hline Max & & 27.0 & 3014.0 & 2542 & 100.0 \\
\hline Mean & & 7.8 & 1669.8 & 1111 & 99.3 \\
\hline St. Dev. & & 9.8 & 1014.0 & 956 & 1.2 \\
\hline
\end{tabular}
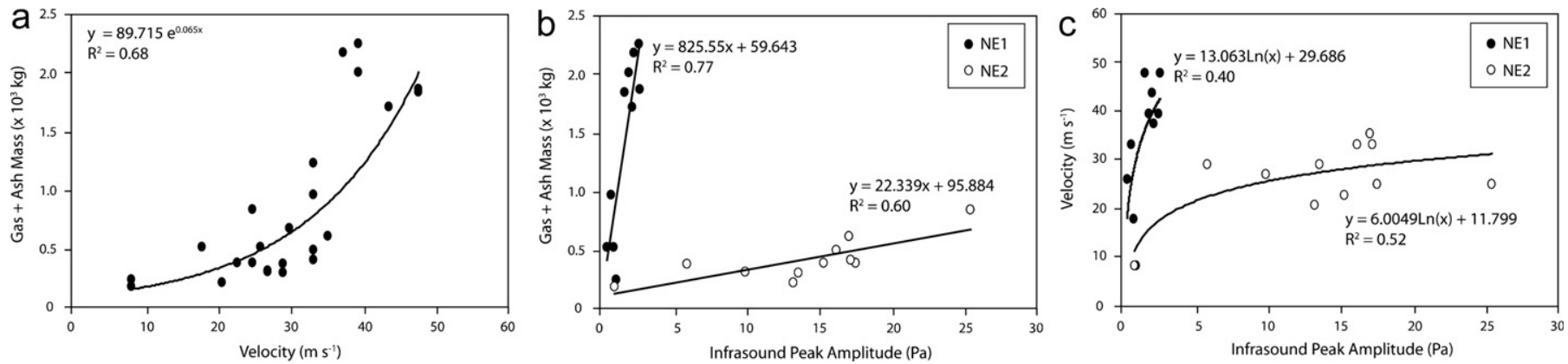

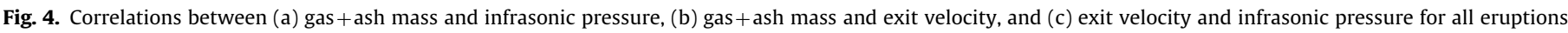
recorded at the NE crater.

- Gas-ash mass and velocity (positive and exponential, Fig. 4a), and hence,

- Source pressure and velocity (weaker, but positive and logarithmic, Fig. 4c),

This series of correlations makes sense. The greater the source pressure, the greater the energy of the explosion and, hence, the greater the gas and ash content as well as emission velocity. However, the lack of correlation between any parameter and mass of the bomb component, i.e., the portion of the plume that follows ballistic trajectories, implies that the mass of bombs does not control the energy of the eruption, nor does the energy of the eruption control the mass of bombs ejected. Instead, the bomb component appears to be an accidental contribution comprising shallow system magma that happens to be entrained by the bursting bubble that generates the explosion, with the amount of entrained (bomb-generating) material varying from eruption to eruption independently of the pressure, or mass of gas and ash, involved. The amount of gas and ash (finer particles that comprise the buoyantly ascending, non-ballistic component of the plume) is, however, a function of the energy of the explosion.

\section{Conclusion}

Erupted magma mass for Vulcanian-to-Plinian eruptions can be obtained from satellite infrared data (e.g., Wen and Rose, 1994) or on the basis of field mapping (e.g., Pyle, 1989; Fierstein and Nathenson, 1992). However, due to the limited extent and cover of deposits from individual normal explosions at Stromboli, as well as danger of close approach, such techniques cannot be applied. We present a new method that uses thermal infrared camera data to extract masses for bomb fields erupted during individual explosive events on the basis of their characteristic power loss. Our results push our estimate for the mass involved in individual eruptions at Stromboli upwards by one order of magnitude to $\sim 10^{4} \mathrm{~kg}$ per eruption. However, our results also indicate that, for Stromboli's normal explosive activity, the mass of magma that comprises the bomb (ballistic) component of the emission plays a passive role in the explosive process, and is not controlled by the explosive processes that generates the gas and ash components of the resulting plume.

\section{Acknowledgments}

This work was greatly improved following the comments of two reviewers (Matthew Patrick and Sonia Calvari), among other things they were responsible for addition of Electronic Supplement 1 and Appendix A. This work was supported by la Région Auvergne and is Laboratory of Excellence ClerVolc contribution $\mathrm{n}^{\circ} 53$. 


\section{Appendix A. Supporting information}

Supplementary data associated with this article can be found in the online version at http://dx.doi.org/10.1016/j.epsl.2013.01. 004 (including Appendices and full data tables).

\section{References}

Allard, P., Carbonnelle, J., Metrich, N., Loyer, H., Zettwoog, P., 1994. Sulfur output and magma degassing budget of Stromboli Volcano. Nature 368, 326-330.

Barberi, F., Rosi, M., Sodi, A., 1993. Volcanic hazard assessment at Stromboli based on review of historical data. Acta Vulcanol. 3, 173-187.

Blackburn, E.A., Wilson, L., Sparks, R.S.J., 1976. Mechanism and dynamics of strombolian activity. J. Geol. Soc. London 132, 429-440.

Bottinga, Y., Weill, D.F., 1970. Densities of liquid silicate systems calculated from partial molar volumes of oxide components. Am. J. Sci. 269, 169-182.

Calvari, S., Büttner, R., Cristaldi, A., Dellino, P., Giudicepietro, F., Orazi, M., Peluso, R. Spampinato, L., Zimanowski, B., Boschi, E., 2012. The 7 September 2008 Vulcanian explosion at Stromboli volcano: multiparametric characterization of the event and quantification of the ejecta. J. Geophys. Res. 117, B05201, http://dx.doi.org/ 10.1029/2011JB009048.

Capaccioni, B., Cuccoli, F., 2005. Spatter and welded air fall deposits generated by fire-fountaining eruptions: cooling of pyroclasts during transport and deposition. J. Volcanol. Geotherm. Res. 145, 263-280.

Cas, R.A.F., Wright, J.V., 1987. Volcanic Successions: Modern and Ancient. Allen \& Unwin, London.

Chouet, B., Hamisevicz, N., McGetchin, T.R., 1974. Photoballistics of volcanic jet activity at Stromboli, Italy. J. Geophys. Res. 79, 4961-4976.

Cigolini, C., Laiolo M., Bertolino, S., 2008. Probing Stromboli volcano from the mantle to paroxysmal eruptions, Geological Society, London, Special Publications, 304, pp. 33-70, 10.1144/SP304.3.

Delle Donne, D., Ripepe, M., 2012. High-frame rate thermal imagery of Strombolian explosions: implications for explosive and infrasonic source dynamics. J. Geophys. Res. 117, B09206, http://dx.doi.org/10.1029/2011JB008987.

Fagents, S.A., Wilson, L., 1993. Explosive volcanic eruptions-VII. The ranges of pyroclasts ejected in transient volcanic explosions. Geophys. J. Int. 113, 359-370.

Fierstein, J., Nathenson, M., 1992. Another look at the calculation of fallout tephra volumes. Bull. Volcanol. 54, 156-167.

Francis, P., Oppenheimer, C., Stevenson, D., 1993. Endogenous growth of persistently active volcanoes. Nature $366,554-557$.

Friedman, J.D., Williams, R.S., 1968. Infrared sensing of active geologic features. In: Proceedings of the 5th Symposium on Remote Sensing of Environment. Ann Arbor (Michigan), University of Michigan Institute of Science and Technology, pp. 787-820.

Ganci, G., Harris, A.J.L., Del Negro, C., Guehenneux, Y., Cappello, A., Labazuy, P., Calvari, S., Gouhier, M. A year of lava fountaining at Etna: volumes from SEVIRI. Geophys. Res. Lett, http://dx.doi.org/10.1029/2012GL051026, in press.

Gouhier, M., Harris, A., Calvari, S., Labazuy, P., Guéhenneux, Y., Donnadieu, F. Valade, S. Lava discharge during Etna's January 2011 fire fountain tracked using MSG-SEVIRI. Bull. Volcanol, http://dx.doi.org/10.1007/s00445-011-0572-y, in press.

Gurioli, L., Harris, A.J.L., Colò, L., Bernard, J., Favalli, M., Ripepe, M., Andronico, D. 2013. Classification, landing distribution, and associated flight parameters for a bomb field emplaced during a single major explosion at Stromboli, Italy, Geology, http://dx.doi.org/10.1130/G33967.1, in press.

Harris, A.J.L., Stevenson, D.S., 1997a. Magma budgets and steady-state activity of Vulcano and Stromboli volcanoes. Geophys. Res. Lett. 24, 1043-1046.

Harris, A.J.L., Stevenson, D.S., 1997b. Thermal observations of degassing open conduits and fumaroles at Stromboli and Vulcano using remotely sensed data. J. Volcanol. Geothem. Res. 76, 175-198.

Harris, A.J.L., Ripepe, M., 2007. Synergy of multiple geophysical approaches to unravel explosive eruption conduit and source dynamics-a case study from Stromboli. Chem. Erde 67, 1-35.

Harris, A.J.L., Dehn, J., James, M.R., Hamilton, C., Herd, R., Lodato, L., Steffke, A 2007. Pahoehoe cooling, discharge and coverage rates from thermal image chronometry. Geophys. Res. Lett. 34, L19303, http://dx.doi.org/10.1029/ 2007GL030791.

Hérdervári, P., 1963. On the energy and magnitude of volcanic eruptions. Bull. Volcanol. 25, 373-385.

Hon, K., Kauahikaua, J., Denlinger, R., Mackay, K., 1994. Emplacement and inflation of pahoehoe sheet flows: observations and measurements of active lava flows on Kilauea Volcano, Hawaii. Geol. Soc. Am. Bull. 106, 351-370.

Jaupart, C., Vergniolle, S., 1988. Laboratory models of Hawaiian and Strombolian eruptions. Nature 331, 58-60.

Jaupart, C., Vergniolle, S., 1989. The generation and collapse of a foam layer at the roof of a basaltic magma chamber. J. Fluid. Mech. 203, 347-380.

Keszthelyi, L., Harris, A.J.L., Dehn, J., 2003. Observations of the effect of wind on the cooling of active lava flows. J. Geophys. Res. 30 (19), SDE 4-1-4-4, http://dx. doi.org/10.1029/2003GL017994.

Lautze, N.F., Houghton, B.F., 2007. Linking variable explosion style and magma textures during 2002 at Stromboli volcano, Italy. Bull. Volcanol. 69, 445-460.

Parfitt, E.A., 2004. A discussion of the mechanism of explosive basaltic eruptions. J. Volcanol. Geoth. Res 134, 77-107.

Parfitt, E.A., Wilson, L., 1995. Explosive volcanic eruptions-IX. The transition between Hawaiian-style lava fountaining and Strombolian explosive activity. Geophys. J. Int. 121, 226-232.

Patrick, M., 2005. Ph.D. Thesis, Geology and Geophysics, University of Hawaii.

Patrick, M.R., 2007. The gas content and buoyancy of strombolian ash plumes. J. Volcanol. Geotherm. Res. 166, 1-6.

Patrick, M.R., Harris, A.J.L., Ripepe, M., Dehn, J., Rothery, D., Calvari, S., 2007. Strombolian explosive styles and source conditions: insights from thermal (FLIR) video. Bull. Volcanol. 69, 769-784, http://dx.doi.org/10.1007/s00445006-0107-0.

Peck, D.L., 1978. Cooling and vesiculation of Alae lava lake, Hawaii. USGS Prof. Pap. 935-B, 59

Pyle, D.M., 1989. The thickness, volume and grainsize of tephra fall deposits. Bull. Volcanol. 51, 1-15.

Ripepe, M., Rossi, M., Saccorotti, G., 1993. Image analysis of the dynamical behavior at Stromboli. J. Volcanol. Geotherm. Res. 54, 335-351.

Ripepe, M., Ciliberto, S., Della Schiava, M., 2001. Time constraints for modeling source dynamics of volcanic explosions at Stromboli. J. Geophys. Res. 106 (B5), 8713-8727.

Ripepe, M., Harris, A.J.L., Carniel, R., 2002. Thermal, seismic and infrasonic insights into conduit process at Stromboli volcano. J. Volcanol. Geotherm. Res. 118, 207-285.

Rosi, M., Bertagnini, A., Landi, P., 2000. Onset of the persistent activity at Stromboli Volcano (Italy). Bull. Vulcanol. 62, 294-300.

Rosi, M., Bertagnini, A., Harris, A.J.L., Pioli, L., Pistolesi, M., Ripepe, M., 2006. A case history of paroxysmal explosion at Stromboli: timing and dynamics of the April 5, 2003 event. Earth Planet. Sci. Lett. 243, 594-606.

Rowland, S.K., Harris, A.J.L., Wooster, M.J., Amelung, F., Garbeil, H., Wilson, L., Mouginis-Mark, P.J., 2003. Volumetric characteristics of lava flows from interferometric radar and multispectral satellite data. Bull. Volcanol 65, 311-330.

Scandone, R., 1979. Effusion rate and energy balance of Paricutin eruption (19431952), Michoacan, Mexico. J. Volcanol. Geotherm. Res. 6, 49-59.

Vergniolle, S., Brandeis, G., Marechal, J.C., 1996. Strombolian explosions 2. Eruption dynamics determined from acoustic measurements. J. Geophys. Res. 101, 20449-20466.

Verhoogen, J., 1946. Volcanic heat. Am. J. Sci. 244 (11), 745-771.

Walker, G.P.L., 1973. Explosive volcanic eruptions, a new classification scheme. Geol. Rund. 62, 431-446.

Washington, H.S., 1917. Persistence of vents at Stromboli and its bearing on volcanic bearing. Bull. Geol. Soc. Am. 28, 249-278.

Wen, S., Rose, W.I., 1994. Retrieval of sizes and total masses of particles in volcanic clouds using AVHRR bands 4 and 5. J. Geophys. Res. 99 (D3), 5421-5431.

Wilson, L., Self, S., 1980. Volcanic explosions clouds: density, temperature, and particle content estimates from cloud motion. J. Geophys. Res. 85 (B5), 2567-2572.

Wooster, M.J., Wright, R., Blake, S., Rothery, D.A., 1997. Cooling mechanisms and an approximate thermal budget for the 1991-1993 Mount Etna lava flow. Geophys. Res. Lett. 24 (24), 3277-3280.

Yokoyama, I., 1957. Energentics in active volcanoes. 2nd paper. Bull. Earthquake Res. Inst. 35, 75-97. 